\title{
CÓRREGO PIRAJUSSARA: RESPIRAR PARA REVIVER
}

PIRAJUSSARA STREAM: BREATHE TO REVIVER

\section{Marli Aparecida Perim}

Arquiteta e Urbanista, Mestre em Ciências Ambientais pela Universidade de Taubaté

\section{RESUMO}

O presente artigo trata da infraestrutura verde como uma ferramenta para aperfeiçoar a relação entre cidade e natureza e minimizar os efeitos da urbanização, motivando a resiliência dos ecossistemas urbanos. Este trabalho analisa a proposta de destamponamento dos córregos urbanos como contribuição aos projetos de corredores verdes, voltados a proporcionar maior sustentabilidade urbana. Mais especificamente foi estudado o caso do córrego Pirajussara, pertencente a bacia do rio Pinheiros, na cidade de São Paulo, tamponado na maior parte de sua extensão. A proposta de destamponamento, a exemplo de realizações em outros países, atinge a várzea do rio Pinheiros, junto ao corredor verde Ibirapuera-Villa Lobos, partindo da Cidade Universitária (CUASO), um dos núcleos do corredor Ibirapuera-Villa Lobos, aumentando a colaboração dos recursos hídricos no projeto de corredor verde. O trabalho foi parte da disciplina Desenho Ambiental, do programa de pós-graduação da Faculdade de Arquitetura e Urbanismo da Universidade de São Paulo. A incorporação do córrego destamponado ao corredor amplia a utilização do espaço verde pela população dos bairros do entorno e cria mais um espaço de resiliência urbana.

Palavras-chave: destamponamento; naturalização; corredor verde; Pirajussara; cidade sustentável.

\begin{abstract}
This article focuses the green infrastructure as a tool to improve the relationship between city and nature as well as to minimize the effects of urbanization, motivating the resilience of urban ecosystems. It is also analyzed the proposal to uncover urban channeled streams as a contribution to green corridor projects, aiming to provide better urban sustainability. It was analyzed more specifically the case of the Pirajussara Stream, which was channeled at most of its length and belongs to the Pinheiros River
\end{abstract}


basin, in São Paulo City. The proposal of this settlement, like the results achieved in other countries, includes the Pinheiros River floodplain, near the green corridor Ibirapuera-Villa Lobos, which starts at Cidade Universitária (CUASO) - one of the cores of Ibirapuera-Villa Lobos corridor - in a way to increase collaboration of hydric resources in the green corridor project. The work is part of the discipline Environment Design of the postgraduate program of the School of Architecture and Urbanism of the University of São Paulo. The inclusion of the uncovered stream to that corridor enlarges the use of green space by the population of surrounding neighborhoods and creates another area of urban resilience.

Keywords: uncovering channeled streams; naturalization; green corridor; Pirajussara; sustainable city.

\section{INTRODUÇÃO}

Os cursos d'água, notadamente os rios, tiveram papel histórico na construção da maioria parte das cidades brasileiras. Os recursos hídricos sempre cumpriram o importante papel de dar suporte para infraestrutura da vida urbana, fornecendo água, drenagem, energia, transporte. O homem dominou a natureza em busca de suprir suas necessidades, construiu cidades, mas não se preocupou com a preservação da paisagem.

Após séculos de utilização sem medida ou planejamento, os recursos hídricos localizados na zona urbana passaram a serem vistos como problema para as cidades, responsáveis pelas inundações e os efeitos delas no trânsito, acúmulo de detritos e proliferação de doenças. A mancha urbana cresceu nessas cidades e os rios foram sendo abandonados. Nas grandes e médias cidades brasileiras, que se desenvolveram às margens dos rios, eles foram sendo paulatinamente escondidos, por meio de intervenções que alteraram seus cursos e aniquilaram suas margens. (HERZOG, 2013).

O crescimento das cidades fez crescer, também, a falta de áreas verdes e de espaços públicos livres, limitando o lazer e a integração da população urbana. A crescente preocupação com o meio ambiente e o estudo da paisagem, a partir da década de 1960 resgatou o papel dos rios como elementos importantes da construção da paisagem e para a qualidade de vida da população. A partir de 1990 cresce a proposta da construção de corredores verdes/caminhos ecológicos, retornando aos trabalhos de Frederi- 
ck Law Olmsted, de fins do século 19 e também se amplia o debate sobre as cidades sustentáveis e resilientes, entendida a resiliência como a capacidade do ecossistema em manter ou retornar às suas condições originais após um distúrbio provocado por forças naturais ou pela ação humana (FRANCO 2010).

A disciplina Desenho Ambiental passa a estudar as questões ecológicas e valores ligados a paisagem, com o objetivo de retomar a interação entre ocupação humana e natureza, considerando a ação do homem sobre o espaço habitado como formador da paisagem.

As novas concepções sobre a "cidade que queremos" resulta em projetos urbanos ancorados em elementos naturais e, em especial, as bacias hidrográficas, como os parques lineares, ciclovias às margens dos cursos d'água e corredores verdes urbanos, conceito surgido no final do século XX.

A carência desses espaços faz com que as legislações municipais normatizem sobre a criação e manutenção de parques e áreas verdes. Os Planos Diretores da cidade de São Paulo (PDEs), dos anos de 2002 e 2004 já previam a criação de mais áreas verdes e parques lineares no entorno dos cursos d'água como medida de proteção e conservação do meio ambiente.

Passados mais de 10 anos do Plano Diretor de 2002, a c idade de São Paulo conta com 24 parques lineares. Em 1914, após discussões realizadas junto à população por cerca de 9 meses, o Plano Diretor Estratégico do Município de São Paulo (PDE), aprovado e sancionado em 31 de julho de 2014, traçou diretrizes, estratégias e medidas visando um uso mais racional dos recursos ambientais e à melhoria da qualidade de vida para a cidade.

O PDE de 2014 prevê a criação de 167 parques, somados aos 105 já existentes, objetivando a ampliação dos espaços verdes e livres da cidade e a criação de mecanismos de financiamento como o Fundo Municipal de Parques, o pagamento por prestação de serviços ambientais aos proprietários ou possuidores de imóveis que reconhecidamente preservam áreas que prestam relevantes serviços ambientais para a sustentabilidade da cidade. 


\section{A INFRAESTRUTURA VERDE}

O conceito de "infraestrutura verde" tem significado diferente, de acordo com o contexto no qual ele é empregado: pode referir-se ao plantio de árvores que tragam benefícios ecológicos em áreas urbanas ou a estruturas de engenharia tais como manejo de enchentes ou tratamento de águas. No Planejamento e Desenho Ambiental, a Infraestrutura Verde refere-se à rede interconectada de áreas verdes naturais e outros espaços abertos que conservam valores e funções ecológicas, sustentam ar e água limpos e ampla variedade de benefícios para as pessoas e a vida selvagem (Franco, 2010).

A infraestrutura verde possibilita a transformação de áreas densamente construídas e habitadas em espaços atrativos, restabelecendo a relação cotidiana do homem com os cursos d'água e expandindo a consciência ecológica. Os corredores são idealizados para requalificar as áreas degradadas ambientalmente, ao mesmo tempo em que reestrutura o tecido urbano e contribui para a interação homem e meio natural. (HERZOG,2013)

As áreas verdes existentes e futuras, para se constituírem em infraestrutura verde, devem ser organizadas e entendidas como redes verdes interconectadas. Nelas os grandes parques e áreas protegidas são as "áreas-núcleo" principais, os parques lineares, ruas e avenidas arborizadas são "corredores verdes", que funcionam como "links" de conexão. Para Franco (2010), a metodologia de desenvolvimento de projetos de desenho ambiental deve ser diferenciada das formas tradicionais de planejamento urbano, porque vai além do aspecto estético para alcançar as preocupações ambientais. Por isso, propõe a utilização de "cenários ambientais", consistentes em projeções de situações futuras para o meio ambiente, com soluções para os problemas ambientais. A infraestrutura verde eficiente é a que possibilita o uso de meios de transporte não motorizado e não poluente, como o modo de andar a pé e o transporte ciclo-viário em suas ligações, no caso, seus corredores verdes, com apoio de sistema metroviário.

Cecília Herzog (2013), explicita propostas de ocupação e uso solo como tentativas de solucionar o conflito natureza $X$ cidade e o potencial para criação de espaços livres que resgatem a presença dos cursos d'água e sua importância paisagística para o cotidiano urbano e para a relação cultura/paisagem. 


\section{RECUPERAÇÃO DE RIOS URBANOS}

Experiências internacionais, nas últimas décadas, de destamponamento de rios e córregos urbanos, com o objetivo de reinseri-los na paisagem urbana, conectá-los a espaços públicos e valorizar seus serviços ao meio ambiente, são notórias em países como Coréia do Sul, Grã-Bretanha, Austrália, Japão, Espanha, México.

A revitalização dos cursos d'água urbanos exige intervenções em diversas escalas, não se restringindo a favorecer a restabelecimento dos elementos naturais, como flora e fauna, mas a possibilitar o aumento da consciência ecológica da população e a resiliência urbana (SILVA, 2017).

Recuperar os rios urbanos, naturalizar suas margens e reurbanizar seu eu entorno significa resgatar a relação holística com os cursos d'água. Não é uma volta ao passado simplesmente, mas uma revitalização da cultura e memória da população atingida, resgatando o sentimento de pertencimento dos elementos naturais da cidade aos seus cidadãos. Os córregos urbanos, em sua maioria, tamponados nas grandes e médias cidades brasileiras, são elementos de interesse para a projeção de infraestrutura verdes, e, notadamente, corredores verdes urbanos, uma vez que pertencem a mesma bacia hidrográfica dos rios urbanos e, na maioria dos casos, foram transformados em vias de acesso para bairros populosos das cidades.

Na cidade de São Paulo, estado de São Paulo, Brasil, já na década de 1930, o plano de Avenidas do Engenheiro Francisco Prestes Maia previu estrutura viária para a cidade de São Paulo apoiada nas várzeas, vinculando construção de avenidas à canalização de córregos e rios. Na década de 1970 a urbanização dos córregos passava pela canalização e pavimentação, dando lugar a grandes avenidas de fundo de vale, por meio do Programa de Canalização de Córregos e Construção de Avenidas de Fundo de Vale (Provac). (TRAVASSOS, 2013).

No Brasil, e especificamente na cidade de São Paulo, até o fim dos anos de 1990 a política em relação aos cursos d'água foi baseada na canalização dos córregos e construção de reservatórios. Brocaneli e Stuerner (2008) mencionam programa da gestão municipal que canalizou mais de sessenta quilômetros de cursos d'água, criando avenidas de fundo de vale. 
Nas últimas décadas assistimos iniciativas de gestões públicas, na cidade de São Paulo, como o Programa Córrego Limpo e a construção de Parques Lineares, no sentido de atenuar a degradação dos córregos existentes nos bairros periféricos e criar espaços públicos para a população do entorno, porém, após alguns anos da implantação desses projetos a alteração dos fatores físicos, como o aumento da taxa de impermeabilização e a consequente alteração da dinâmica das bacias hidrográficas, das quais os córregos urbanos fazem parte, descaracterizam os espaços e, por vezes os condenam ao desuso.

O Plano Diretor Estratégico, de 2004, previa um "Programa de Recuperação Ambiental de Cursos d'água e Fundos de Vale, considerando o sistema de rios e córregos como estruturantes do território, mas não foi efetivamente implementado, e tampouco os afluentes dos cursos d'água, como os córregos, foram incluídos nos projetos.

O PDE da cidade de São Paulo, aprovado em 2002 apontava como objetivos urbanísticos e ambientais estratégicos relacionados à recuperação e proteção da rede hídrica ambiental, em seu artigo 25, a ampliação das áreas permeáveis ao longo dos fundos de vales e cabeceiras de drenagem, as áreas verdes significativas e a arborização, ampliação os parques urbanos e lineares para equilibrar a relação entre o ambiente construído e as áreas verdes e livres e garantir espaços de lazer e recreação para a população, articular, através de caminhos de pedestres e ciclovias, preferencialmente nos fundos de vale, as áreas verdes significativas, os espaços livres e os parques urbanos e lineares. O PDE de 2002 já previa, também, a bacia hidrográfica como unidade territorial de estudo e planejamento da rede hídrica ambienta, constituída esta de cursos d'água, cabeceiras de drenagem, nascentes, olhos d'água e planícies aluviais, e dos parques urbanos, lineares e naturais, áreas verdes significativas e áreas protegidas. O artigo 272, do PDE de 2002 previa, ainda, um Programa de Recuperação de Fundos de Vale, composto por intervenções urbanas em saneamento, drenagem, implantação de parques lineares e urbanização de favelas, objetivando ampliar as áreas verdes permeáveis ao longo dos fundos de vales, criando progressivamente parques lineares e minimizando os fatores causadores de enchentes e os danos delas decorrentes, mapear e georreferenciar as nascentes, aprimorar o desenho urbano, ampliando e articulando os espaços de uso público, em especial os arborizados e destinados à circulação e bem-estar dos pedestres, construir, ao longo dos parques lineares, vias de circulação de pedestres e ciclovias, entre outras medidas. 


\section{CORREDOR VERDE}

FRANCO (2010) define os corredores verdes como espaços lineares de uso múltiplo para preservar a qualidade ambiental nas cidades, proteger beiras d'água, fundos de vale e linhas de cumeeira. Os corredores são constituídos de pontos, linhas e planos. A conexão entre os pontos, linhas e planos, somados aos pontos arquitetônicos e culturais existentes na área alcançada pelo corredor o identifica como ponto de resiliência urbana do ponto de vista ecológico, ou seja, a capacidade da cidade para enfrentar crises de qualidade de vida.

Para Franco (2010), a ideia de corredores verdes e/ou ecológicos, parte da premissa de que os modelos de parques, praças e jardins urbanos já não resolvem a necessidade de qualidade ambiental das cidades, que exige uma visão mais sistêmica e interdisciplinar, em busca de uma cidade mais sustentável ecologicamente.

O bioclimático Ken Yeang (2009), na busca do eco-design, discorre sobre a integração das infraestruturas cinza (engenharia), azul (água), vermelha (humana) e verde (paisagem) em projetos de todas as escalas. A ideia de camadas (rede sobre redes) é mencionada por Vital (2012), considerando a vegetação como camada (layer) verde e os cursos d'água como camada (layer) azul.

A ideia de infraestrutura verde considera privilegiar as camadas (layers) verde (vegetação) e azul (cursos d'água) nos projetos de sustentabilidade urbana. Nesse sentido, utilizar os córregos, como elementos a serem incorporados, ou seja, conectados ao Corredor Verde, otimiza a camada azul da infraestrutura.

\section{CORREDOR IBIRAPUERA VILLA LOBOS}

O corredor verde Ibirapuera Villa Lobos como proposta no curso de pós-graduação da Faculdade de Arquitetura e Urbanismo da Universidade de São Paulo. Trata-se de um corredor em uma das áreas mais privilegiadas em matéria de áreas verdes e iniciativas de esporte e cultura, que conquistaram trechos isolados com ciclovias, como é o caso do trecho inicial da Avenida Faria Lima, junto à Avenida Pedroso de Morais, ou mesmo o circuito ciclo-viário, que acontece aos domingos, na Avenida República do Líbano, junto à linha perimetral do Parque Ibirapuera (FRANCO 2010). 
A proposta do Corredor Verde Ibirapuera-Villa Lobos surge dentro de um ideário por parte dos cidadãos paulistanos de "reconquista das várzeas", e no caso deste corredor, a "reconquista da várzea do Rio Pinheiros" (Fig. 1).

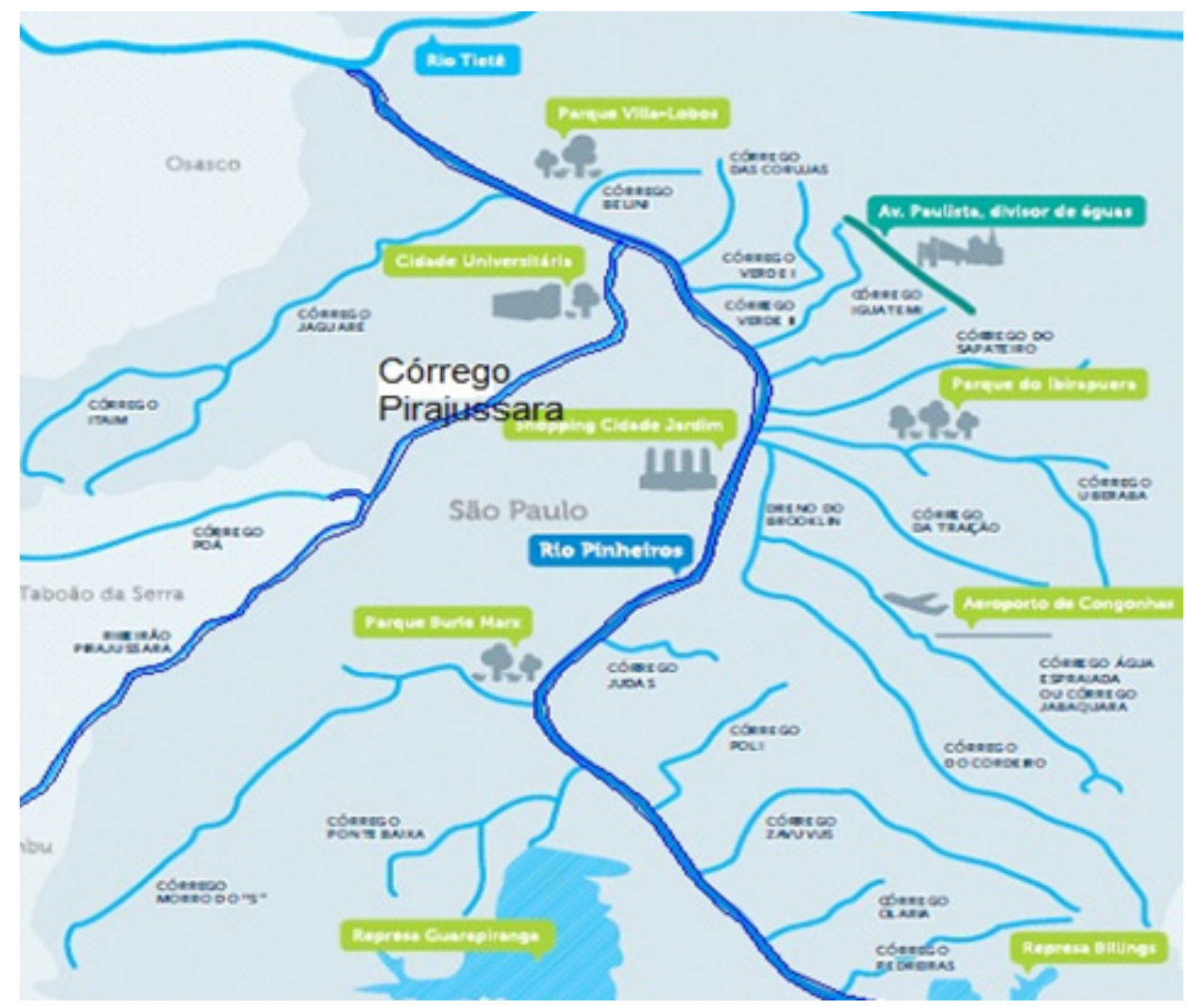

FIGURA 1. Desenho da Bacia do Rio Pinheiros - Fonte: Associação Águas Claras do Rio Pinheiros, adaptado.

A área tem como núcleos os parques - Ibirapuera, Villa Lobos, Parque do Povo e Parque Alfredo Volpi - e as áreas institucionais da Cidade Universitária e do Instituto Butantã, todas elas áreas públicas, e como linha o rio Pinheiros. No entanto, as atividades descritas bem como o modo de andar a pé ainda são muito restritas aos parques e algumas ruas arborizadas, por falta de infraestrutura verde projetada para esse fim, uma vez que tanto os pedestres quanto os ciclistas correm sérios riscos em sua integridade física e psíquica (no caso assaltos e violência). Para dar efetividade a proposta falta as ligações entre as partes, ou seja, os chamados "links" (FRANCO 2010).

A proposta delimitou um trecho da várzea do Rio Pinheiros, abrangendo na margem direita, os distritos de Moema, Itaim-Bibi, Jardim Paulista, Pinheiros, Alto de Pinheiros e Vila Leopoldina e na margem esquerda, os distritos do Morumbi e Butantã. Foi 
elaborado um Cenário de Planejamento e Desenho Ambiental onde se projetou uma Infraestrutura Verde dentro do conceito de resiliência urbana. O projeto prevê como infraestrutura verde uma rede de calçadas e ciclovias que permeie a várzea do Rio Pinheiros, possibilitando a reconquista dos espaços abertos urbanos para o caminhar e o uso da bicicleta (FRANCO, 2010).

Além dos "Núcleos" e "Ligações" Verdes", o Corredor conta com os corpos d'água existentes (Rio Pinheiros, Raia Olímpica da Cidade Universitária, conjunto lacustre do Parque do Ibirapuera), sendo previstos quatro Parques Lineares propostos e rede de caminhos de mobilidade ecossocial, composto por calçadas ecológicas e sistema de ciclovias (fig. 2).

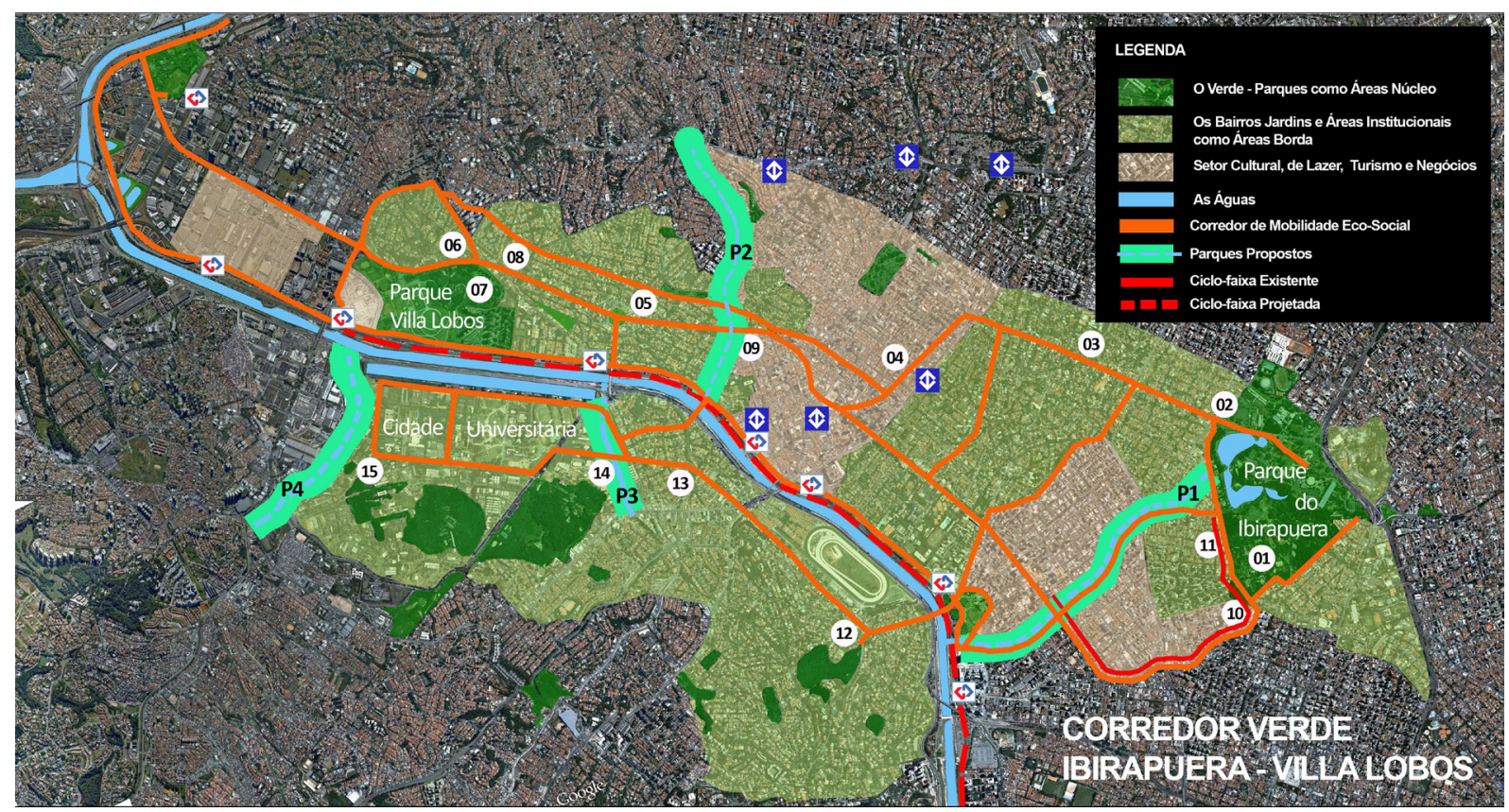

FIGURA 2. Proposta do Corredor Verde Ibirapuera-Villa Lobos Fonte: Revista Labverde, 2010

A partir de visita técnica ao corredor Ibirapuera-Villa Lobos proposto, constatamos que os córregos pertencentes às bacias hidrográficas envolvidas no projeto estão, em sua maioria, tamponados. É o caso dos córregos Verde I, Verde II, Sapateiro, Belini, Pirajussara e outros.

\section{PROPOSTA DE DESTAMPONAMENTO DO PIRAJUSSARA}

O presente trabalho debruça-se sobre os dados e situação atual do córrego Pirajussara, apontado na proposta do Corredor Verde Ibirapuera Villa Lobos, como o Parque 
Linear "3", como estudo de caso, objetivando analisar a contribuição de seu destamponamento a um projeto de corredor verde, envolvendo o rio Pinheiros, como é o caso do corredor verde Ibirapuera Villa Lobos.

A análise se valeu dos mapas digitais do sistema Geosampa, disponibilizados pela Prefeitura Municipal de São Paulo e a proposta do Corredor Verde Ibirapuera Villa Lobos, elaborado em artigo da Professora Doutora Maria de Assunção Ribeiro Franco.

\section{ÁREA DE ESTUDO: O CÓRREGO PIRAJUSSARA}

A bacia do córrego Pirajussara é parte da bacia hidrográfica do rio Pinheiros e está localizada no setor oeste da Região Metropolitana de São Paulo, em uma área de aproximadamente $72 \mathrm{~km}^{2}$, abrangendo os municípios de São Paulo $-36,5 \mathrm{Km}^{2}$, ou $50 \%$ da área, Taboão da Serra - $20 \mathrm{~km}^{2}$, cerca de $28 \%$, e Embu - 15,5 $\mathrm{Km}^{2}$, aproximadamente $22 \%$ da área da bacia. Apresenta a forma alongada, na direção SudoesteNordeste, largura entre 3 a $5 \mathrm{Km}$, nos trechos baixo e médio, atingindo até 6 a $7 \mathrm{Km}$ no montante. A densidade da drenagem é de média a alta. O trecho inferior da bacia desenvolve-se da foz até a confluência com o ribeirão Poá, e o trecho superior, desse ponto até as nascentes. Central e linearmente à bacia, encontra-se o rio Pirajussara, com uma extensão de 18.577 metros, sendo 6.285 canalizados. Seu principal afluente é o ribeirão Poá. A bacia apresenta uma amplitude topográfica de até 120 metros, desenvolvendo-se desde a desembocadura até os divisores da bacia do rio EmbuMirim. Quanto à ocupação a bacia é quase totalmente ocupada, com predominância de edificações de padrão inferior.

A Região da Bacia do córrego Pirajussara situa-se entre os distritos do Butantã, Morumbi, Vila Sônia, Raposo Tavares, Vila Andrade, Campo Limpo e Capão Redondo no município de São Paulo, além do município de Taboão da Serra e parte do município de Embu.O Córrego Pirajussara nasce em Embu das Artes e marca a divisa do município de São Paulo, com os municípios de Embu das Artes e Taboão da Serra. Com aproximadamente $18,5 \mathrm{~km}$ de extensão ele é afluente da margem esquerda do rio Pinheiros, passando por dentro da Cidade Universitária, em área pertencente a universidade de São Paulo. O córrego é tamponado no trecho que vai da Rua Moncorvo Filho até a rua João Santucci, ao final da Avenida Pirajussara, já no município de Taboão da Serra (fig.3). 


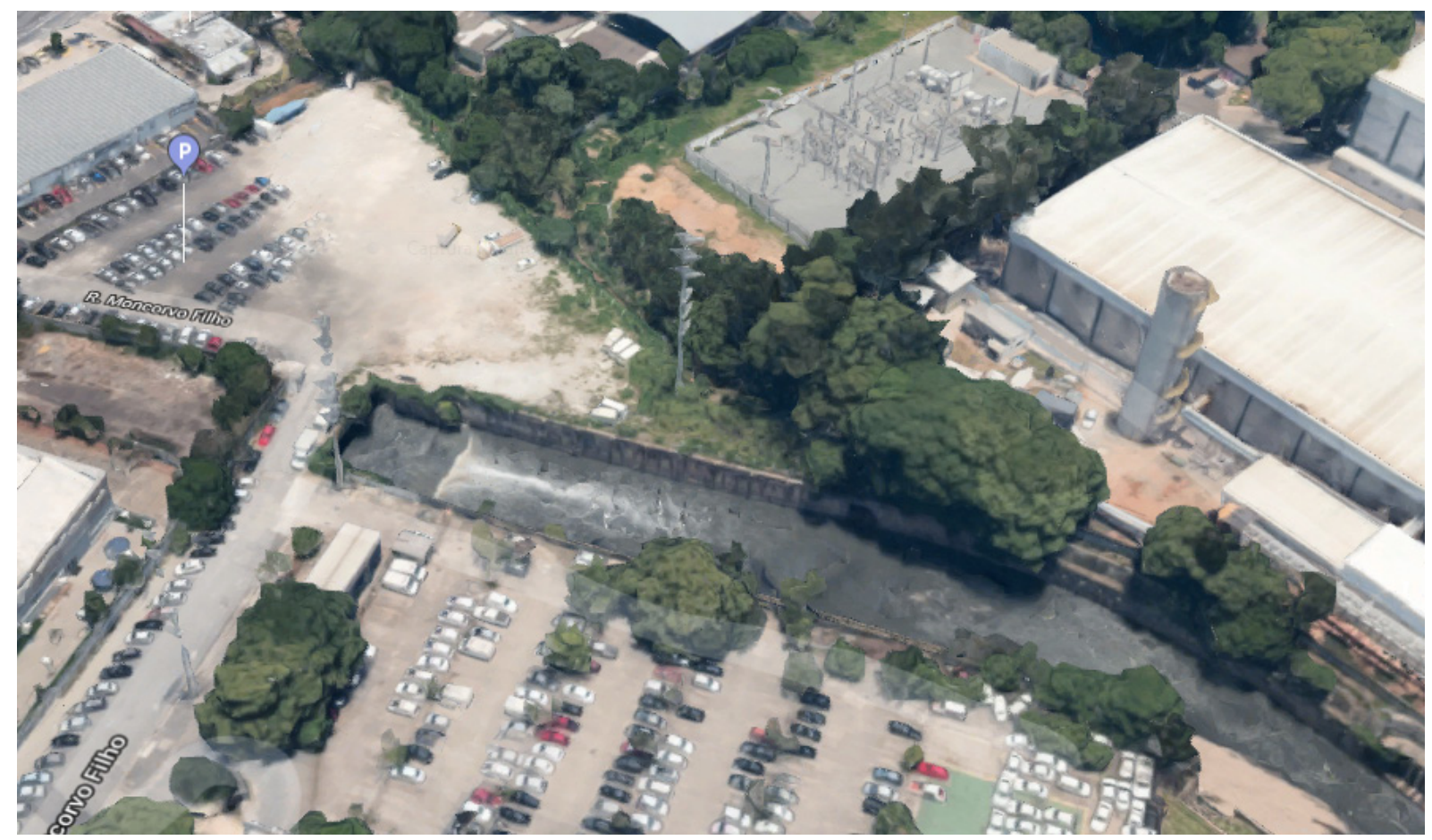

FIGURA 3. Início do tamponamento do Córrego Pirajussara.

Fonte: Google Earth, acessado em maio/2018.

\section{AVENIDA ELISEU DE ALMEIDA - CÓRREGO PIRAJUSSARA TAMPONADO}

Em visita à Avenida Eliseu de Almeida, bairros Vila Pirajussara, Jardim Instituto da Previdência e Rolinópolis, via pública sobre o córrego Pirajussara tamponado, que a partir da Vila Sônia passa a ser denominada Av. Pirajussara, constatamos que no espaço correspondente ao córrego canalizado foi instalada uma ciclovia que vai da Rua até a altura do número 4700 a Avenida Pirajussara, que é continuação da Avenida Eliseu de Almeida, desenhada no centro do espaço ocupado pela Avenida (fig. 4). 


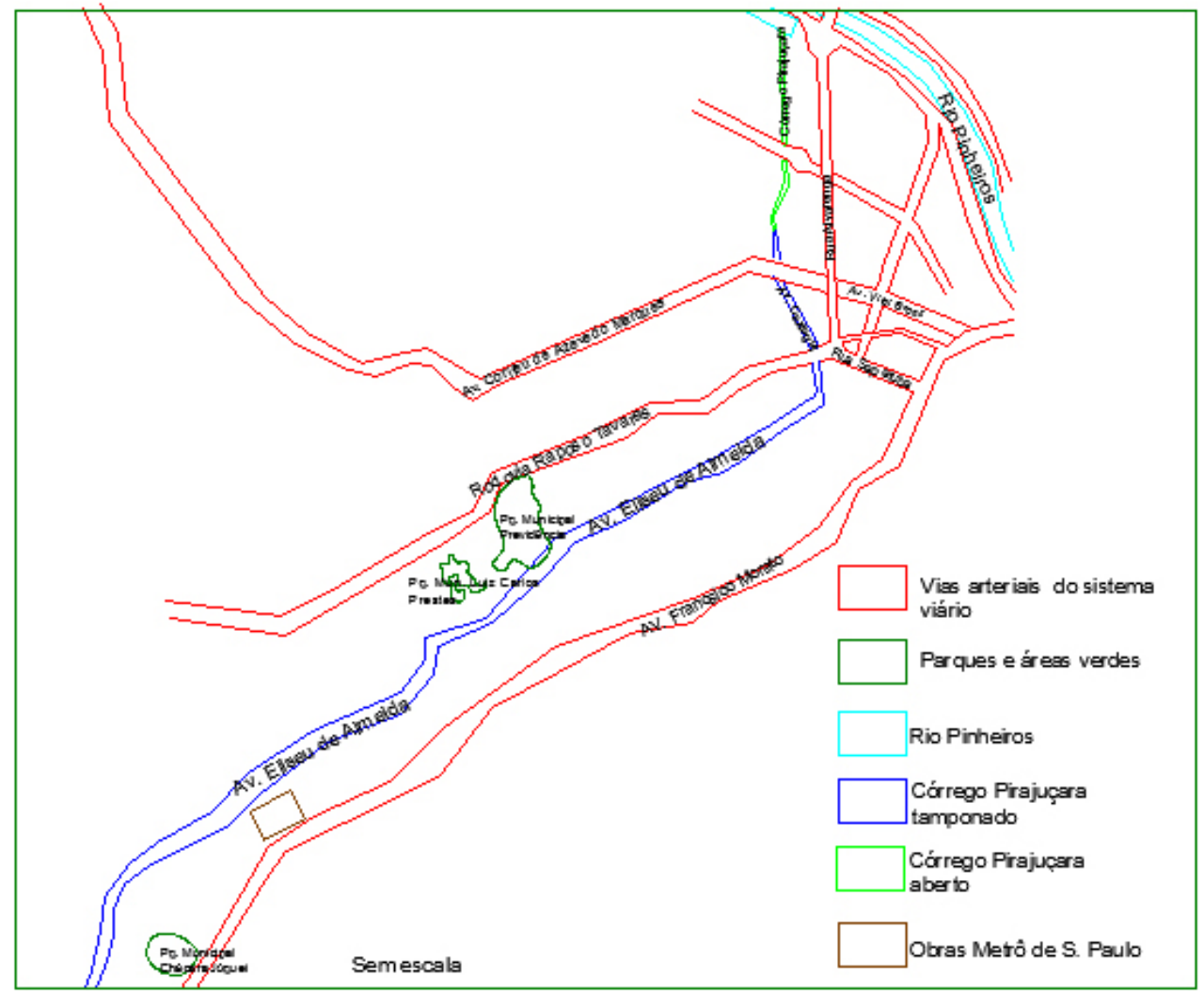

FIGURA 4. O córrego Pirajussara, sob a Avenida Eliseu de ALmeida.

Fonte: Autora, maio/2018.

Sobre o córrego tamponado foi implementada ciclovia, porém, sem nenhum espaço verde ou mobiliário urbano como bancos ou equipamento de recreação (fig. 5).

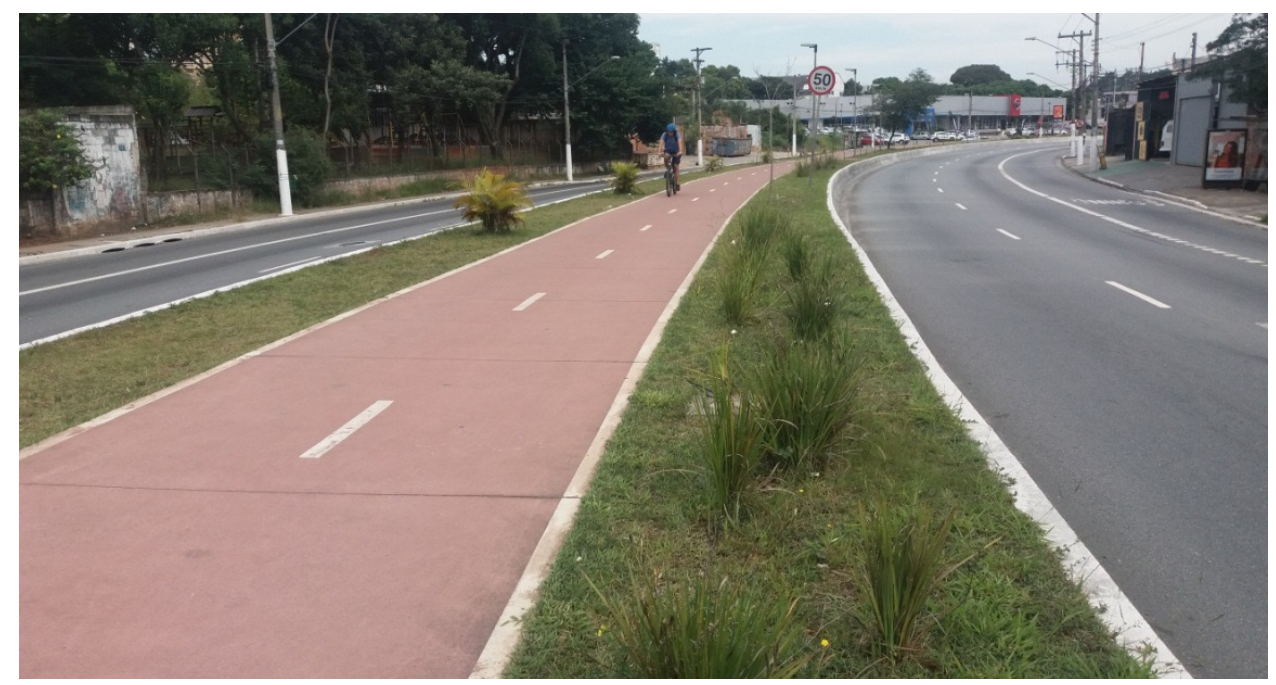

FIGURA 5. Área verde quase inexistente junto ao Córrego Pirajussara tamponado. Fonte: Autora, maio/2018. 
AAvenida Eliseu de Almeida é via arterial, de tráfego intenso, que liga a zona oeste de São Paulo ao município de Taboão da Serra (fig. 6).

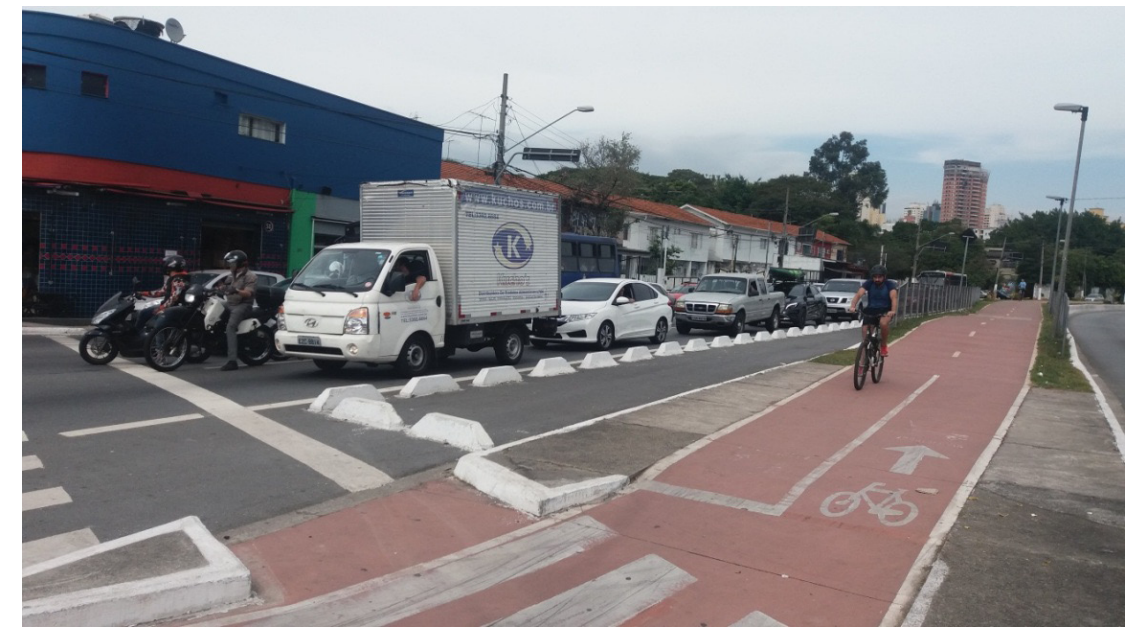

FIGURA 6. Tráfego intenso na Avenida Eliseu de Almeida. Fonte: Autora, maio/2018.

As Avenidas Eliseu de Almeida e Pirajussara têm histórico de enchentes, a ponto de a população reivindicar junto às autoridades municipais sua canalização, no decorrer das décadas de 1970 a 1990 (OSTROWSKY, 2000).

Na extensão da Avenida há algumas áreas verdes públicas e particulares, que podem ser utilizadas como manchas verdes num futuro corredor verde (fig. 7).

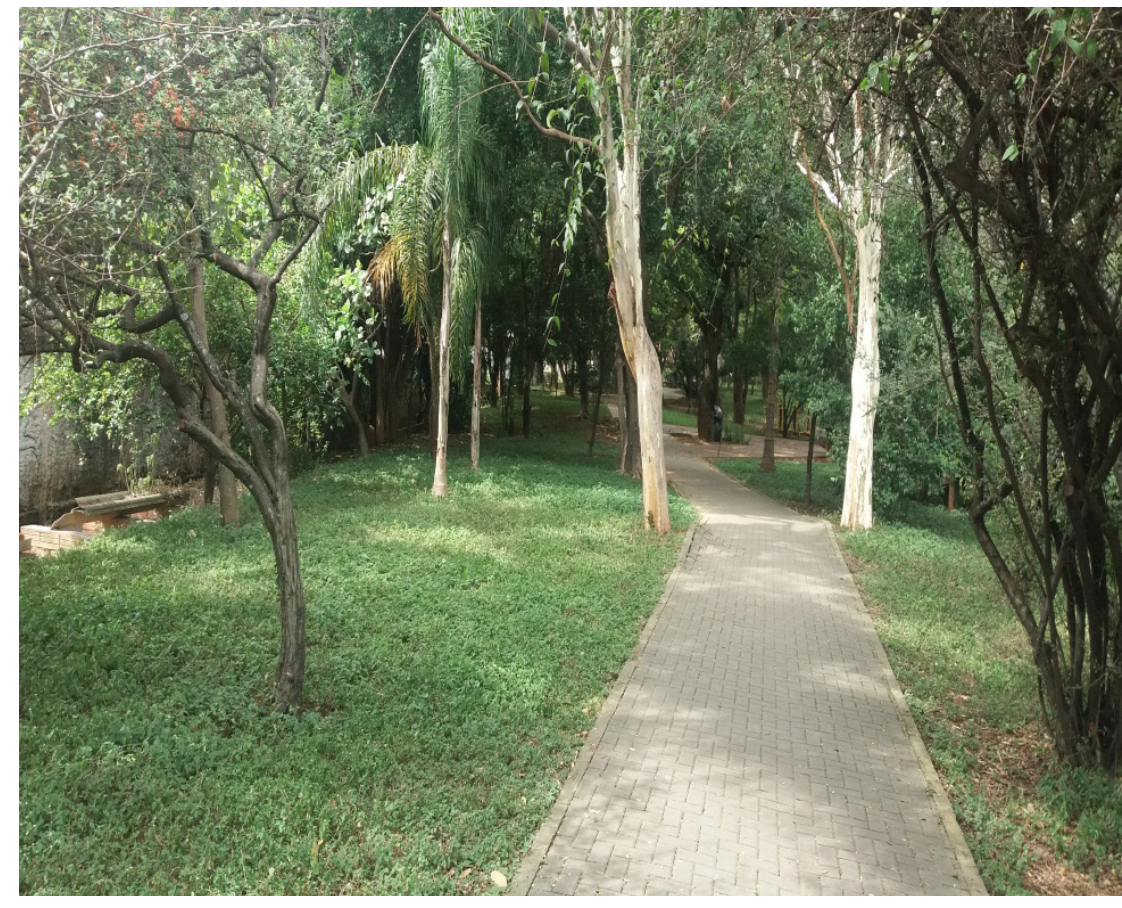

FIGURA 7. Praça Euclides Parente Ramos, na Avenida Eliseu de Almeida. Fonte: Autora, maio/2018. 
Há três parques, situados próximos a linha do córrego Pirajussara: o Parque da Previdência, com 91.500 metros quadrados, no Jardim da Previdência, próximo à Rodovia Raposo Tavares. Suas águas drenam diretamente para o córrego do Pirajucara, em seu trecho canalizado sob a Avenida Eliseu de Almeida, e parte para um de seus afluentes, o Pirajussara-Mirim, que só encontra com o Pirajussara mais a jusante, junto da Cidade Universitária; o Parque Luís Carlos Prestes, com 27.100, no Jardim Rolinópolis, distrito do Butantã, encontra-se em fundo de vale, no qual correm as águas de um dos vários afluentes do córrego Pirajussara, uma área com encostas de forte declividade e cobertura vegetal de boa qualidade. Auxilia na conservação da rede hídrica da cidade; sua vegetação protege as encostas da erosão e melhora a qualidade das águas; O Parque Chácara do Jockey, que possui uma área de $143.500 \mathrm{~m}^{2}$, entre as avenidas Prof. Francisco Morato e Avenida Pirajussara continuação da Avenida Eliseu de Almeida (fig. 8).

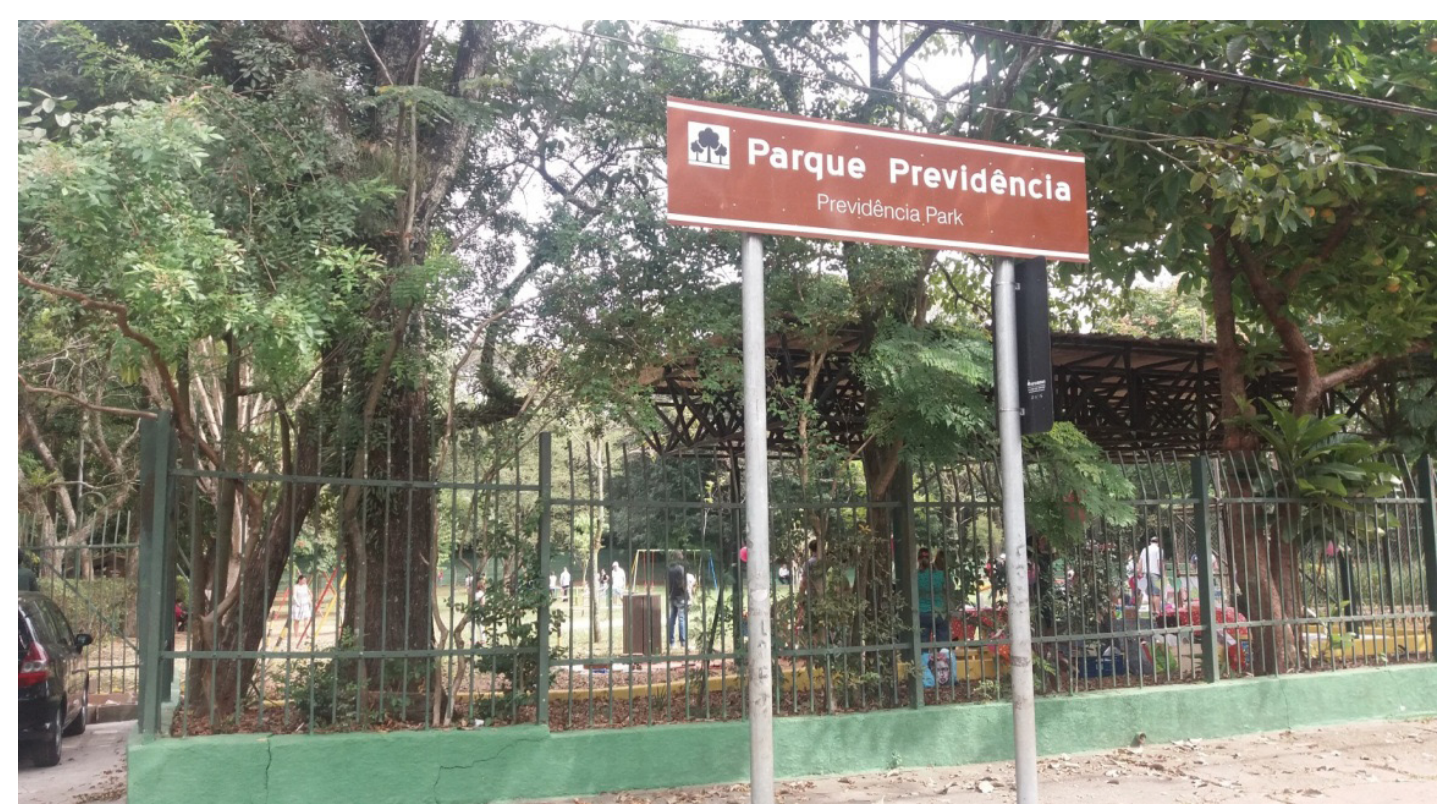

FIGURA 8. Parque Previdência, área verde do entorno do Córrego Pirajussara.

Fonte: Autora, maio/2018.

\section{A CONECTIVIDADE COM O CORREDOR VERDE IBIRAPUERA VILLA LOBOS}

Os Parques e áreas verdes particulares do entorno do córrego canalizado têm potencial para serem conectados ao corredor verde, proporcionando um uso integrado, com mobilidade para o andar a pé e de bicicleta, desde que estabelecidos links entre eles e o corredor verde já existente (fig. 9). 


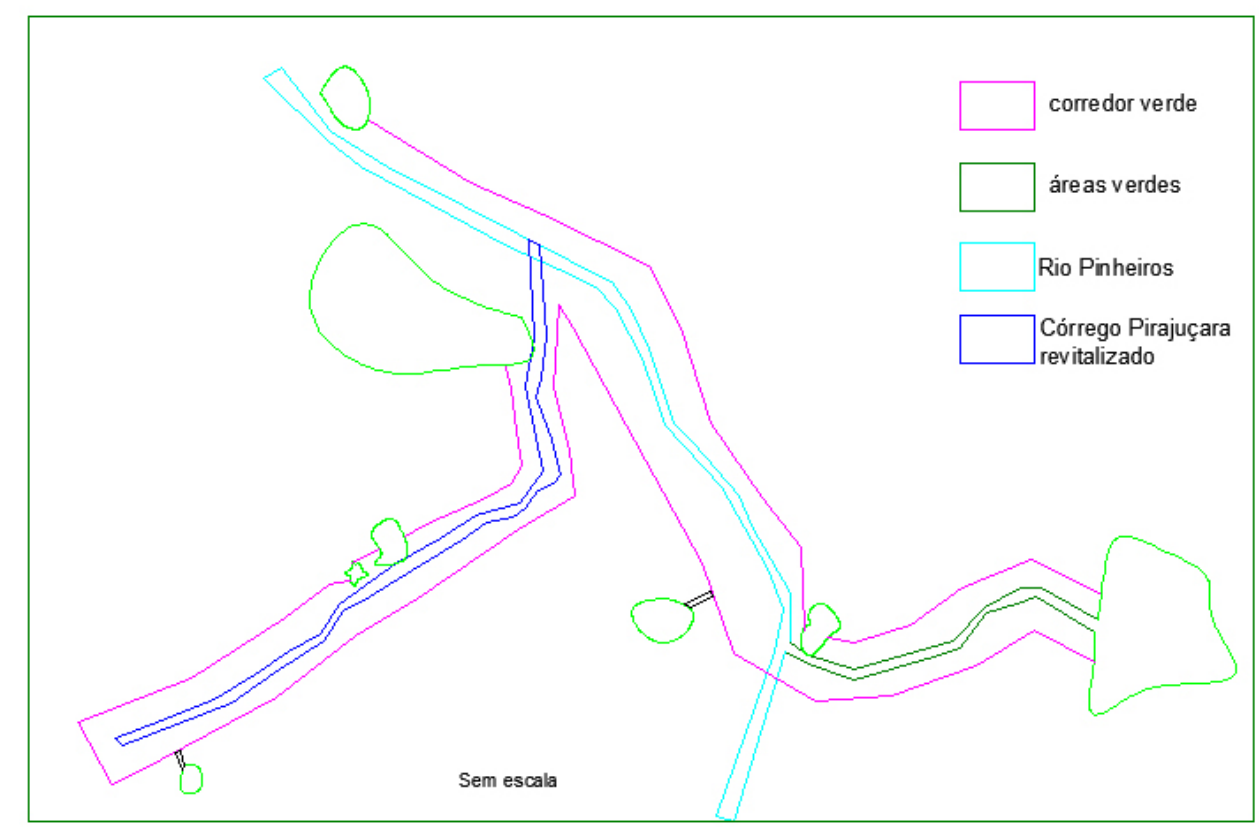

FIGURA 9. Proposta de conexão entre Corredor Ibirapuera e Villa Lobo e Pirajussara. Fonte: Autora, maio/2018.

Artigo publicado na Revista Estudos Avançados, noticia projeto do ano de 2009, discutido com a comunidade de destamponamento do córrego Pirajussara e Parque Linear, em ocasião e em resposta há possibilidade de construção de um túnel, pelo consórcio empresarial encarregado da construção da "Linha Amarela", do Metrô de São Paulo, que passaria sob o Parque da Previdência (GONÇALVES, 2005). No entanto, túnel e Parque Linear não se concretizaram, restando a canalização e tamponamento do córrego Pirajussara, com pouco e malconservado espaço verde, calçadas não ecológicas, ouseja sem espaço verde e para pedestres, ocasionando conflito entre veículos, pedestres e ciclistas (fig. 10).

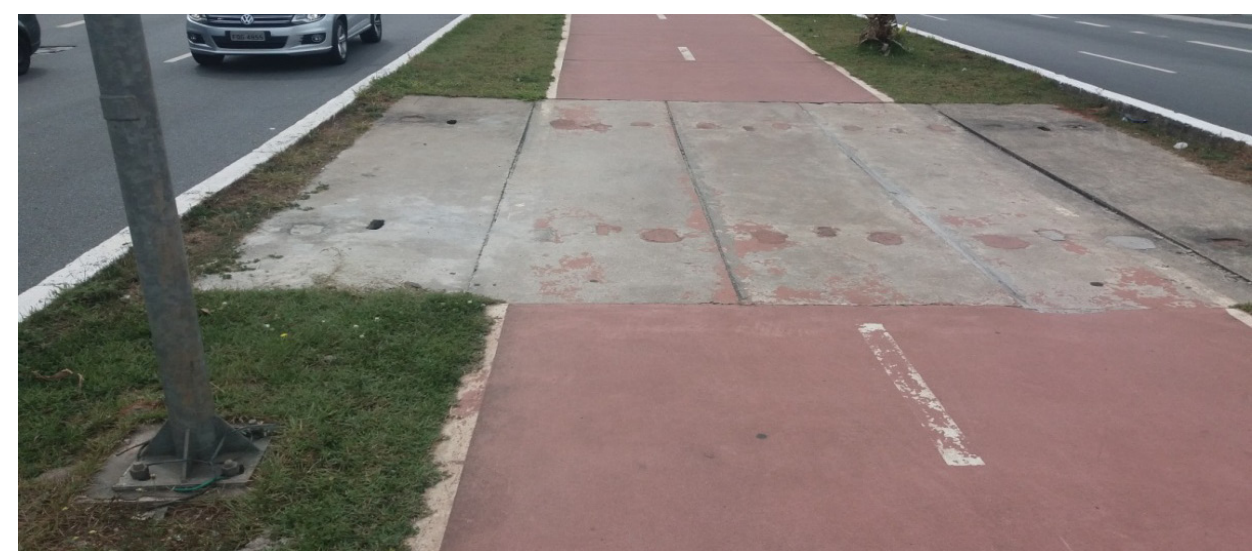

FIGURA 10. Espaço verde restrito e mal conservado. Fonte: Autora, maio/2018. 
Uma intervenção para tornar o córrego Pirajussara e seu entorno num corredor verde e azul, com funções ecológica, social, econômica e cultural. A infraestrutura do rio e do parque linear seriam contribuintes de um desenvolvimento sustentável para a região, melhorando o microclima, aumentando a permeabilidade do solo, reduzindo a poluição e embelezando a cidade. A conexão com o corredor Ibirapuera-Villa Lobos é possível pelas ruas Moncorvo Filho, nos limites do Instituto Butantã, em que o córrego já se encontra tamponado, cruzando a Avenida Vital Brasil e seguindo pela Avenida Caxingui até a Avenida Eliseu de Almeida, em que se inicia a ciclovia existente. Está em construção mais uma estação de metrô, Vila Sônia, em gleba de terra situada entre a Avenida Francisco Morato e a Avenida Eliseu de Almeida, na altura em que a Avenida passa a ser denominada Pirajussara, fator que proporcionará, a médio prazo, melhor acesso ao corredor e maior mobilidade urbana (fig.11).

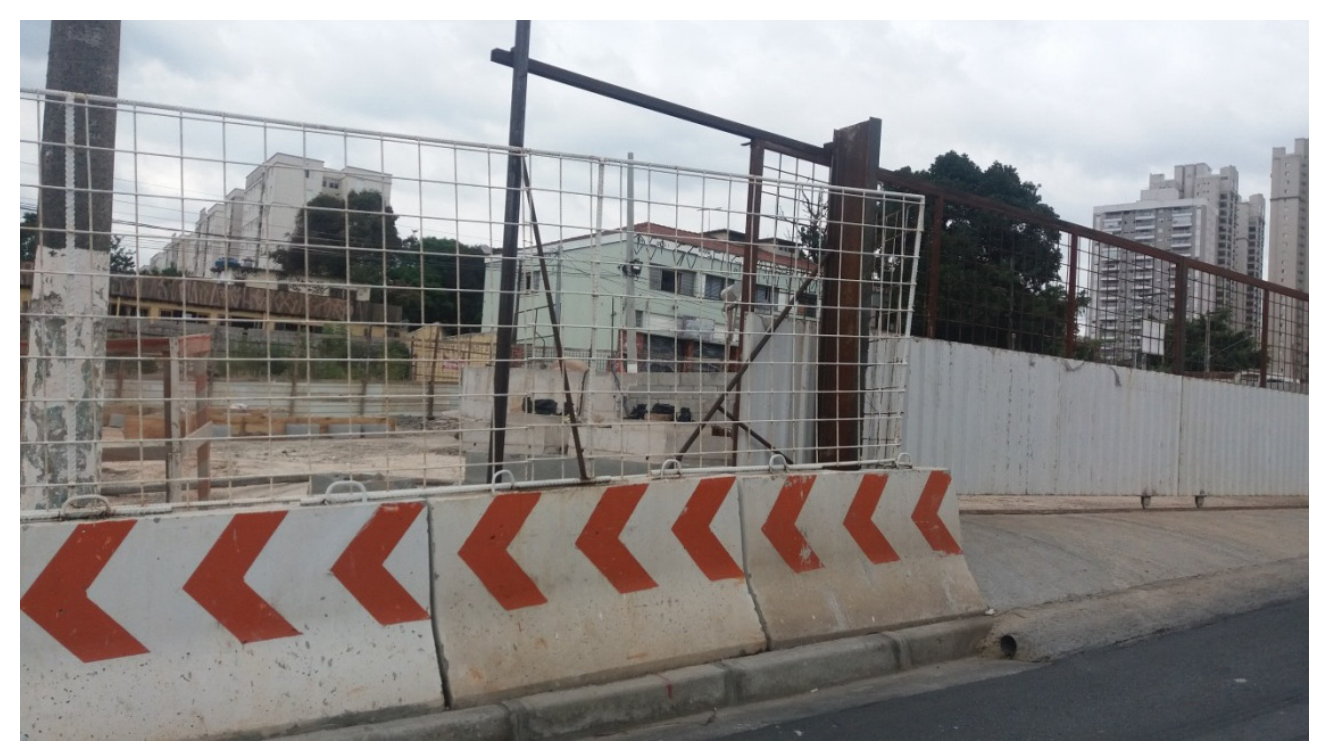

FIGURA 11. Obras da Estação Vila Sônia, do Metrô de São Paulo.

Fonte: Autora, maio/2018.

A implementação da conexão dos corredores Ibirapuera-Villa Lobos e Pirajussara pressupõe:

a) recriar a paisagem natural do entorno do rio, visando atrair a fauna e a flora para dar suporte a sua recuperação;

b) estabelecer zona de transição entre o meio urbano construído e o meio natural;

c) tratamento das águas de serem lançadas no córrego; 
d) impedir o depósito de lixo em suas margens;

e) criação de um parque linear no entorno do rio, de fácil acesso para pedestres e ciclistas;

f) ligação por meio de acesso para pedestres e ciclistas aos parques existentes nas áreas próximos;

f) existência de equipamentos para recreação e lazer que envolva os moradores, para que se estabeleça uma relação de convívio com o rio, gerando mais consciência da responsabilidade pela sua preservação;

g) programas de divulgação sobre a história e a importância do córrego para a cidade;

h) atividades físicas, esportivas e culturais ao longo do percurso do rio;

i) alterar a leito carroçável da Avenida Eliseu de Almeida e promover as desapropriações necessárias.

\section{CONCLUSÃO}

O destamponamento de córregos urbanos, como elemento integrante na criação de corredores verdes urbanos é possível e traz benefícios à cidade. A ampliação de áreas verdes, a volta dos cursos d'água na paisagem das cidades e o acesso mais democrático a estas áreas, trazem ganhos significativos para a qualidade de vida das pessoas, incentivadas a praticar a hábitos de urbanidade já esquecidos como a conversa de rua, a caminhada, o passeio ciclístico. O meio ambiente também ganha em qualidade do ar, aumento de permeabilidade do solo, retorno da fauna e salubridade. A ecologia e a rotina urbana caminham no sentido de um equilíbrio. Se a água dos rios e córregos urbanos forem tratadas, a longo prazo, deixa de ser poluída, melhorando a qualidade da água de toda bacia hidrográfica, trazendo benefícios regionais.

O destamponamento e revitalização do córrego Pirajussara amplia a execução da proposta do Corredor Verde Ibirapuera Villa Lobos, implementando o Parque Linear "3" proposto, reintegrando este curso d'água à paisagem urbana, trazendo de volta, a médio prazo, a biodiversidade e contribuindo para o desenvolvimento sustentável da cidade. 


\section{BIBLIOGRAFIA}

ÁGUAS CLARAS DO RIO PINHEIROS, Rio Pinheiros e seu território: conhecer para transformar. $1^{\text {a }}$ EDIÇÃO, SÃO PAULO, 2017.

BROCANELI, P. F.; STUENER, M. M. Renaturalização de rios e córregos no município de São Paulo. Exacta, v. 6, n. 1, São Paulo, p. 147-156, 2008.

FRANCO, M. A. R., Infraestrutura Verde em São Paulo: o caso do Corredor Verde Ibirapuera-Villa Lobos. Revista LABVERDE, São Paulo, v. 1, p. 135-154, set. 2010.

FRANCO, M. A. R. Desenho ambiental. Uma introdução à arquitetura da paisagem com o paradigma ecológico. São Paulo, Annablume, FAPESP, 2003.

FRANCO, M.A.R., Infraestrutura Verde para a Resiliência Urbana às Mudanças Climáticas da cidade de São Paulo. Revista LABVERDE, São Paulo, v. 1, p. 92-115, set. 201.

GORSKI, M. C. B., Rios e cidades: ruptura e reconciliação. Dissertação (Mestrado em Arquitetura e Urbanismo) - Universidade Presbiteriana Mackenzie, São Paulo, 2008.

GONÇALVES, F. M., Ibirapuera-Villa Lobos. Operação urbana consorciada Vila Sônia e a possibilidade de diálogo. Estudos Avançados 25 (71), 2011.

HERZOG, C. P. Cidades Para Todos: (re)aprendendo a conviver com a natureza. Rio de Janeiro: Inverde, 2013.

OSTROWSKY, M. S. B. Sistemática integrada para controle de inundações em sub-bacias hidrográficas urbanas, estudo de caso: a Bacia do Córrego Pirajussara sob o enfoque da integração de obras com ações de educação e percepção ambiental. Tese (Doutorado). FAU - Faculdade de Arquitetura e Urbanismo. São Paulo; 2000.

SÃO PAULO (Município) Plano Diretor Estratégico do Município de São Paulo: 2002- 2012. São Paulo, SENAC, Prefeitura Municipal, 2004.

SILVA, J. C. de A, da. Bacias Hidrográficas Urbanizadas. Renaturalização, Revitalização e Recuperação: estudo de caso da Bacia do Jaguaré. Tese de Doutorado, USP, 2007.

TRAVASSOS, L. R. F. C. Revelando rios. Novos paradigmas para a intervenção em fundos de vale na cidade de São Paulo. Tese de Doutorado, Programa de Pós-Graduação em Ciência Ambiental, Universidade de São Paulo, 243 p, 2010. 